\title{
Effects of mothers' locus of control for child improvement in a developmentally delayed sample.
}

Timothy B. Smith

Brigham Young University, tbs@byu.edu

Matthew N.I. Oliver

University of South Dakota

Glenna C. Boyce

Utah State University

Mark S. Innocenti

Utah State University

Follow this and additional works at: https://scholarsarchive.byu.edu/facpub

Part of the Counseling Psychology Commons

\section{Original Publication Citation}

Smith, T. B., Oliver, M. I., Boyce, G. C., \& Innocenti, M. S. (2000). Effects of mothers' locus of control for child improvement in a developmentally delayed sample. The Journal Of Genetic Psychology: Research And Theory On Human Development, 161(3), 307-313. doi:10.1080/ 00221320009596713

\section{BYU ScholarsArchive Citation}

Smith, Timothy B.; Oliver, Matthew N.I.; Boyce, Glenna C.; and Innocenti, Mark S., "Effects of mothers' locus of control for child improvement in a developmentally delayed sample." (2017). Faculty Publications. 1969.

https://scholarsarchive.byu.edu/facpub/1969

This Peer-Reviewed Article is brought to you for free and open access by BYU ScholarsArchive. It has been accepted for inclusion in Faculty Publications by an authorized administrator of BYU ScholarsArchive. For more information, please contact ellen_amatangelo@byu.edu. 
Smith, T. B., Oliver, M. N. I., Boyce, G. C., \& Innocenti, M. (2000). Caregivers' locus of control for child improvement. Journal of Genetic Psychology, 161, 307-313.

\title{
Caregivers' Locus of Control for Child Improvement in a Developmentally Delayed Sample ${ }^{1}$
}

\author{
Timothy B. Smith \\ Brigham Young University \\ Matthew N. I. Oliver \\ University of South Dakota \\ Glenna C. Boyce \\ Mark S. Innocenti \\ Early Intervention Research Institute \\ Utah State University
}

\footnotetext{
${ }^{1}$ Work reported in this paper was supported in part with funds from the U.S. Department of Education (Contract \#HS90010001) to the Early Intervention Research Institute at Utah State University.
} 


\begin{abstract}
A potentially important variable that has received little attention in the literature is the locus of control a caregiver holds for child improvement, including its influence on the caregiver's treatment compliance and on actual child improvement. To evaluate the utility of the construct in a practice setting, 131 caregiver-child dyads were evaluated across one year. Children were approximately four years old at the first assessment, and all of them had been diagnosed with a developmental disability. Caregiver compliance to treatment (attendance at sessions and teacher ratings of their support and knowledge) was tracked, and measures of child development status and caregiver locus of control were administered. Statistical results indicated that caregiver locus of control was not significantly correlated with gains in the child's development over the year. Caregiver beliefs about whether the child or chance would be responsible for improvement were associated with lower compliance to treatment, whereas caregiver beliefs that child improvement was due to professional intervention were associated with enhanced involvement in treatment.
\end{abstract}




\section{Caregivers' Locus of Control for Child}

Improvement in a Developmentally Delayed Sample

Traditionally, locus of control (LOC) has been conceptualized as a dichotomy between the notion that one has control over life events and the contrasting belief that life events are caused by external factors such as fate or powerful others. Although much past and current research has used Rotter’s (1966) unidimensional scale of external vs. internal LOC (e.g., Gerits \& Ce-Brabander, 1999; Mischel, Zeiss, \& Zeiss, 1974), some researchers have criticized the unidimensional model as too simplistic and have suggested instead the use of multidimensional scales for measuring LOC (e.g., Connell, 1985; DeVellis et al., 1985). For example, in a factor analysis done by Connell (1985), internal and external causes were described as two separate dimensions rather than as opposite poles of a single construct. Moreover, Devellis et al. (1985) note that, theoretically (Fishbein \& Ajzen, 1975), content-specific LOC scales are more likely to predict specific behaviors.

Some researchers have evaluated caregiver LOC and found that it is related to caregiver-child interactions and to caregiver involvement (Affleck, McGrade, Allen, \& McQueeney, 1985; Helm, Comfort, Bailey, \& Simeonsson, 1990). In a study with clear implications for practice, DeVellis, DeVellis, and Spilsbury (1988) found that a multidimensional approach to understanding caregivers' LOC supports the assumption that the extent to which caregivers view their child's condition as either controllable or non-controllable is associated with the type and amount of treatment they seek and implement. If a caregiver has an external locus of control, believing that improvement is due to fate rather than due to professional treatment, the child is more likely to receive 
less professional treatment and less caregiver involvement than children whose caregivers believe otherwise. This reduced caregiver support of professional treatment may subsequently result in reduced functional progress among the children.

Data reported by Maisto and German (1981) support this assumption that caregiver LOC predicts child developmental change. They found that internal LOC among mothers of infants with developmental delays was associated with significant cognitive and language gains in the infants over a four-year study. However, rather than using a multidimensional scale to measure caregiver LOC, Maisto and German used the unidimensional Rotter Internal-External Locus of Control scale in their study. Furthermore, they did not account for the mediating variable of caregiver compliance with treatment. In contrast, the present study sought to evaluate the effects of caregiver LOC on both caregiver compliance to treatment and longitudinal child developmental gains, using a multidimensional measure of LOC specific to the improvement of children's functioning. By this approach, the specific types of LOC beliefs that best predict caregiver compliance to treatment and changes in child development could be identified.

\section{Method}

Participants were 131 mother-child dyads enrolled in one of two center-based early intervention programs for children with developmental delays. All children received classroom-based preschool services, two and one half hours per day five days per week during the time of this investigation, which was part of a larger longitudinal examination of the effects of those services. (For additional information, see Innocenti, Hollinger, Escobar, \& White, 1993). Children were predominantly Caucasian (91\%), 
with an average age of 52.3 months at the beginning of the study; $44 \%$ were female. All children had been identified by pediatric specialists as being moderately to severely developmentally delayed in their motor, cognitive, or language abilities. The mothers' average age was 32.7 years, their average education was 13.9 years, and their average household income was $\$ 28,000$.

At two assessments conducted exactly twelve months apart, a standardized measure of developmental functioning (the Battelle Developmental Inventory [BDI; Newborg, Stock, Wnek, Guidubaldi, \& Svinicki, 1984]) was administered to each child. The age-adjusted BDI total score at pre-test was subtracted from the age-adjusted total score at post-test to estimate the gains in developmental status over the year between assessments. Five subscales of the BDI (Personal/Social, Adaptive Behavior, Motor, Communication, and Cognitive) were used to evaluate whether caregiver LOC beliefs were related to specific aspects of child development over time.

A multidimensional measure of primary caregiver locus of control for child improvement, the Child Improvement Locus of Control Scales (CILC; Devillis et al., 1985), was administered to the child's mother at the same time. The CILC assesses the degree to which a caregiver attributes change in the child's condition to (1) professionals, (2) divine influence, (3) the parent (self), (4) the child, and (5) chance. These five sources of attribution, the CILC subscales, were measured across multiple items with Likert-type scales ranging from 1 to 5 , with higher scores indicating greater endorsement. Both the CILC and the BDI have demonstrated acceptable reliability and validity in previous studies (Glascoe \& Byrne, 1993; Devillis et al., 1985; Newborg et al., 1984). 
To assess the level of caregiver involvement in the child's treatment program, an interventionist blind to the purpose of the study tracked caregiver attendance at treatment sessions and rated the caregivers on their knowledge about the child's condition and their supportiveness of treatment, including compliance with service requests. Higher ratings on the Likert-type scales indicated greater levels of involvement. Ratings were found to have acceptable reliability (alpha $=.87$ ), and a factor analysis found that all items loaded above .80 on a single factor accounting for $81.5 \%$ of the variance, providing evidence of construct validity.

\section{Results}

To investigate differences across the five CILC subscales, multivariate analyses of variance and post-hoc univariate tests were performed. These analyses revealed that at both assessments the caregivers endorsed the Child and Parent subscales more $(\underline{p}<.001)$ than the Professional and Divine Influence subscales, which they endorsed more $(\mathrm{p}<$ .001) than the Chance subscale: thus caregivers typically showed stronger internal than external LOC. No subscale differences were related to sex of the caregiver's child.

Descriptive data on the BDI confirmed that this sample of children was moderately to severely developmentally delayed. The age-adjusted total score on the BDI was an average of two standard deviations below the normative mean of $100(\underline{M}=$ 61.1, $\underline{\mathrm{SD}}=15.5)$. No differences were found between the sexes on developmental status. Correlations controlling for the child's developmental status at pre-test indicated that none of the five CILC subscales was meaningfully related to changes in overall child development status $(\mathrm{p}>.10)$. To investigate whether LOC was associated with a specific aspect of child development, correlations controlling for scores at pre-test were also 
conducted for longitudinal changes on each BDI subscale. Because these analyses involved a total of 25 correlations (5 CILC subscales x 5 BDI subscales), the alpha level was set at $\mathrm{p}<.01$ to correct for the increased likelihood of Type I errors. None of the results were statistically significant, indicating no meaningful association between caregiver LOC and changes in child developmental status.

To investigate whether caregiver LOC predicted caregiver involvement in treatment, a regression equation was conducted with the five CILC subscales simultaneously entered. This analysis yielded statistically significant results (Adj. $\underline{\mathrm{R}}^{2}=$ $.17, \underline{F}(5,121)=5.2, \underline{p}<.001)$. As shown in Table 1, the Professional, Chance, and Child subscales were all significant predictors of the caregivers' involvement in treatment, and the Divine Influence and Parent subscales were not meaningfully related to the caregivers' involvement.

\section{Discussion}

Overall developmental changes in this sample of children with disabilities were not related to the multidimensional measure of LOC. Furthermore, none of the specific aspects of development assessed by the BDI subscales were related to caregiver LOC. These findings differ from those reported by Maisto and German (1981), who found that although caregiver LOC did not predict motor development, it did predict the cognitive and communicative aspects.

However, several cautions are recommended in comparing the results of this study with those of Maisto and German (1981). First, the children in this sample were an average of 41 months older than the children evaluated by Maisto and German, and gains in infant development may be more subject to parental influences than gains among 
preschool aged children (e.g., Johnson, 1999). Furthermore, because the largest gains in language and cognition are made before the preschool years (Fernald, Pinto, Swingley, Weinberg, \& McRoberts, 1998), future studies that account for potential age effects are warranted. Second, the present study tracked changes over a one-year period, while Maisto and German assessed gains made over four years. Therefore, it could be that the influence of caregiver LOC accrues over a longer time than one year. Longitudinal examinations that report data at annual intervals would aid in clarifying this issue. Third, this study used a different measure of LOC than did Maisto and German. The use of the multidimensional CILC was based on the theoretical assumption that behavior specific attributions may be more useful than global assessments of LOC (Fishbein \& Ajzen, 1975). However, the CILC has less psychometric support than the widely-used scale based on Rotter's (1966) work. Therefore, although the results of the present study question the benefit of multidimensional assessment of LOC in predicting gains in child development, initial scrutiny of the CILC itself may be in order. Finally, because both this study and that of Maisto and German were correlational, future research may also benefit from investigating the causal path implied by LOC theories by controlling for the opposite explanation that LOC changes as a function of perceived circumstances.

Similar to results reported by DeVellis et al. (1988), the finding of this study that certain caregiver LOC beliefs predict caregiver involvement in a treatment program has implications for both practice and research. For example, by screening LOC beliefs prior to treatment, practitioners may be able to identify caregivers who might limit their participation. Those who attribute change to unpredictable events or to the child seem to be particularly at risk. Practitioners may be able to enhance caregiver participation 
through efforts to enhance their beliefs in the efficacy of professional treatment (Jellinek, 1994).

Given that internal LOC usually predicts initiative and involvement, future research may benefit from investigating why the internal LOC that the caregivers themselves expressed regarding child improvement was not related to their involvement in the professional treatment program. The external LOC that holds the child responsible for improvement was found in this study to negatively predict caregiver involvement; this aspect may also warrant additional research. In this sample, the LOC belief concerning the child's responsibility for improvement was the most commonly endorsed. Similar values that make individuals responsible for their own condition are common in many societies (Furnham, Bond, \& Heaven, 1993). However, this type of belief appears to have the unintended effect of reducing support for the professional treatment of children who are limited in their ability to help themselves. 


\section{References}

Affleck, G., McGrade, B. J., Allen, D. A., \& McQueeney, M. (1985). Mothers' beliefs about behavioral causes for their developmentally disabled infant's condition: What do they signify? Journal of Pediatric Psychology, 10, 293-303.

Connell, J. P. (1985). A new multidimensional measure of children’s perception of control. Child Development, 56, 1018-1041.

DeVellis, B. M., DeVellis, R. F., \& Spilsbury, J. C. (1988). Parental actions when children are sick: The role of belief in divine influence. Basic and Applied Social Psychology, 9, 185-196.

DeVellis, R. F., DeVellis, B. M., Revicki, D. A., Lurie, S. J., Runyan, D. K., \& Bristol, M. (1985). Development and validation of the Child Improvement Locus of Control (CILC) scales. Journal of Social and Clinical Psychology, 3, 307-324.

Fernald, A., Pinto, J. P., Swingley, D., Weinberg, A., \& McRoberts, G. (1998). Rapid gains in speed of verbal processing by infants in the $2^{\text {nd }}$ year. Psychological Science, 9, 228-231.

Fishbein, M., \& Ajzen, I. (1975). Belief, attitude, intention and behavior: An introduction to theory and research. Reading, MA: Addison-Wesley.

Furnham, A., Bond, M., \& Heaven, P. (1993). A comparison of Protestant work ethic beliefs in thirteen nations. Journal of Social Psychology, 133, 185-197.

Gerits, P., \& Ce-Brabander, B. (1999). Psychosocial predictors of psychological, neurochemical and immunological symptoms of acute stress among breast cancer patients. Psychiatry Research, 85, 95-103. 
Glascoe, F. P., \& Byrne, K. E. (1993). The accuracy of three developmental screening tests. Journal of Early Intervention, 17, 368-379.

Helm, J. M., Comfort, M., Bailey, D. B., \& Simeonsson, R. J. (1990). Adolescent and adult mothers of handicapped children: Maternal involvement in play. Family Relations, 39, 432-437.

Innocenti, M. S., Hollinger, P., Escobar, C., \& White, K. (1993). The cost effectiveness of adding one type of parent involvement to an early intervention program. Early Education and Development, 4, 306-326.

Jellinek, M. S. (1994). The outpatient milieu. Journal of the American Academy of Child and Adolescent Psychiatry, 33, 277-279.

Johnson, M. H. (1999). Cortical plasticity in normal and abnormal cognitive development: Evidence and working hypotheses. Psychological Science, 11, 419-437.

Maisto, A. A., \& German, M. L. (1981). Maternal locus of control and developmental gain demonstrated by high risk infants: A longitudinal analysis. Journal of Psychology, 109, 213-221.

Mischel, W., Zeiss, R., \& Zeiss, A. (1974). Internal-external control and persistence: Validation and implication of the Stanford preschool internal-external scale. Journal of Personality and Social Psychology, 29, 265-270.

Newborg, J., Stock, J., Wnek, L., Guidubaldi, J., \& Svinicki, J. (1984). Battelle Developmental Inventory. Allen, TX: DLM Teaching Resources.

Rotter, J. B. (1966). Some implications of a social learning theory for the prediction of goal directed behavior from testing procedures. Psychological Review, 67, 301-316. 
Table 1.

$\underline{\text { Regression model predicting caregiver involvement in treatment from caregiver locus of }}$ control beliefs.

\begin{tabular}{lccccc}
\hline Independent & $\underline{\mathrm{B}}$ & Standard & Beta & $\underline{\mathrm{t}}$ & $\mathrm{p}$ \\
Variable & \multicolumn{2}{c}{ Error } & & \\
& & & & \\
\hline & & & & & \\
CILC Professional & .63 & .26 & .25 & -0.4 & .01 \\
CILC Divine Intervention & -.08 & .22 & -.04 & -0.2 & .82 \\
CILC Parent & -.07 & .32 & -.03 & -2.8 & .006 \\
CILC Chance & -.94 & .33 & -.29 & -2.2 & .02 \\
CILC Child & -.58 & .26 & -.25 & & \\
\hline
\end{tabular}

